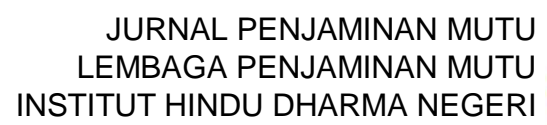

JURNAL PENJAMINAN MUTU

LEMBAGA PENJAMINAN MUTU

INSTITUT HINDU DHARMA NEGERI

Volume 6 Nomor 1 (2020)

ISSN : 2407-912X (Cetak)

ISSN : 2548-3110 (Online)

http://ejournal.ihdn.ac.id/index.php/JPM

\title{
MENINGKATKAN MUTU NILAI KEMANUSIAAN PADA ANAK-ANAK MELALUI SATUA MEN TIWAS TEKEN MEN SUGIH (SEBUAH KAJIAN SEMIOTIKA)
}

\author{
Oleh \\ Ni Made Ayu Susanthi Pradnya Paramitha \\ Universitas Hindu Negeri I Gusti Bagus Sugriwa Denpasar \\ santhipradnyap@gmail.com
}

diterima 11 Januari 2020, direvisi 14 Pebruari 2020, diterbitkan 29 Pebruari 2020

\begin{abstract}
There is one way to form a child's character is with a tale or a story where in Balinese life we called satua or masatua. Satua is a part of lisan literary once as a work of grain Graine literature, unattached to the temple and rhythm as well. Although satua is as one of the local obscension wisdom of the ancestral legacy and has been there for a long time, but this is still relevant to be used as one of the tools in developing way of life, personality, characteristics and a wisdom for people in Bali and of course based on the rule as a Balinese in the community. One of the best example of the satua called "Men Tiwas Teken Men Sugih" or the life between the poor and the rich. By using semiotic Peirce approach, and through the way of life from the poor family in the character, this article would emphasise a moral message regarding the behavior of the decreators. By this means that we can take an example to educate the young children what is the meaning of life and also to increase the quality of humanity to child
\end{abstract}

Keywords: Satua (story telling), Men Tiwas Teken Men Sugih, Semiotic Approach

\begin{abstract}
Abstrak
Salah satu cara membentuk karakter anak adalah dengan mendongeng atau bercerita yang dalam kebiasaan masyarakat Bali disebut nyatua atau masatua. Satua merupakan bagian dari sastra lisan sekaligus sebagai sebuah karya sastra Bali purwa yang bebas, tidak terikat pada bait maupun irama serta anonim. Meskipun sebagai salah satu kearifan lokal warisan leluhur yang telah ada sejak lama, akan tetapi saat ini satua masih sangat relevan digunakan sebagai salah satu acuan dalam menumbuhkembangkan pribadi yang arif, bijaksana, berkarakter, dan bernilai sesuai dengan norma sosial dimasyarakat. Salah satu satua yang penting sebagai pedoman kehidupan manusia adalah satua Men Tiwas Teken Men Sugih. Dengan menggunakan pendekatan Semiotik Peirce, serta melalui sifat-sifat yang ditunjukkan oleh tokoh Men Tiwas, tulisan ini
\end{abstract}


ingin mengungkap pesan moral mengenai tingkah laku yang patut ditiru. Dengan demikian pendidikan melalui satua ini diharapkan mampu meningkatkan mutu nilai kemanusiaan pada anak-anak.

\section{Kata Kunci : Satua, Men Tiwas Teken Men Sugih, Semiotik}

\section{PENDAHULUAN}

Lingkungan menjadi bagian yang amat penting dalam perkembangan kepribadian dan karakter anak. Faktor lingkungan berbanding lurus dengan dampak yang akan diterima dalam perkembangan anak itu sendiri. Lingkungan yang positif akan memberikan dampak yang baik pada anak, begitu pula sebaliknya.

Lingkungan pertama dan utama sebagai awal perjalanan kehidupan manusia adalah lingkungan keluarga. Peran dan fungsi keluarga menjadi sangat penting karena keluarga merupakan tempat yang paling efektif untuk menjalankan berbagai fungsi penting yang diperlukan anak, salah satunya fungsi pendidikan. Apabila keluarga tidak mampu menanamkan kejujuran, semangat untuk maju, tolong-menolong, religiusitas, dan kemampuan-kemampuan dasar lainnya, maka akan sulit bagi anak untuk tumbuh menjadi makhluk sosial yang berkarakter. Oleh karena itu, setiap keluarga harus memiliki kesadaran bahwa karakter anak sangat tergantung pada pendidikan dalam keluarga.

Salah satu cara untuk membentuk karakter anak adalah dengan mendongeng atau bercerita yang dalam kebiasaan masyarakat Bali disebut nyatua atau masatua. Satua merupakan bagian dari sastra lisan. Rafiek menguraikan menguraikan beberapa ciri sastra lisan yakni: (1) lahir dari masyarakat yang polos, belum melek huruf, dan bersifat tradisional; (2) menggambarkan budaya milik kolektif tertentu, yang tidak jelas siapa penciptanya; (3) lebih menekankan aspek khayalan, ada sindiran, jenaka, dan pesan mendidik; (4) sering melukiskan tradisi kolektif tertentu (Indhra, Feerlie Moonthana; Karim, 2018).

Sejalan dengan ciri sastra lisan di atas, maka dapat dikatakan satua sebagai suatu jenis karya sastra Bali purwa yang bebas, tidak terikat pada bait maupun irama serta anonim (tidak diketahui pengarangnya). Bentuknya ada dua yaitu satua tutur/lisan dan satua tulis. Secara implisit satua menyiratkan berbagai gagasan, amanat, dan pesan moral bagi kehidupan masyarakat. Dalam satua tertanam nilai-nilai kebijaksanaan dan penuh kearifan. Hal ini sejalan dengan tujuan pendidikan karakter, yakni mengetengahkan ajaran etika dan norma-norma sosial agar dapat diterima, dipahami, dan diamalkan oleh anak dalam menjalani kehidupannya. Norma dan nilai tersebut tentunya dapat tersampaikan benar pada anak melalui penuturan satua yang tepat, menarik, dan menggunakan bahasa yang mudah dimengerti.

Kajian tentang satua Cupak Teken Grantang, juga menyebutkan satua menjadi bagian dari warisan leluhur yang harus dilestarikan (Andayani, Ni Made Juli; Linggih, I Nyoman; Wiradnyana, 2017). Dikatakan pula tutur merupakan salah satu jenis karya sastra yang mengandung nilai filsafat, agama, dan nilai-nilai kehidupan (Laksmi, 2014). Dalam hal ini, Laksmi mengatakan istilah tutur yang disamakan dengan satua. Penulis lain dengan menelitik pernyataan dari Wellek dan Warren menyatakan bahwa sastra memiliki 3 (tiga) fungsi yakni indah, menyenangkan, dan berguna (Santosa, 2012). Maka jika sastra lisan seperti satua dipelajari dengan sungguh-sungguh, maka fungsi dan manfaatnya akan dapat digunakan dalam kehidupan manusia. Begitu pula dalam tulisan tentang tinjauan filosofis kearifan lokal sastra lisan Ternate menyatakan bahwa kearifan lokal itu sendiri merupakan sebuah manifestasi kebudayaan yang terjadi dengan penguatan-penguatan dalam kehidupannya (Pora, 2014). Hal ini merupakan salah satu bentuk humanisasi manusia dalam kebudayaan. 
Meskipun sebagai salah satu kearifan lokal warisan leluhur yang telah ada sejak lama, akan tetapi saat ini sesungguhnya satua masih sangat relevan digunakan sebagai salah satu acuan dalam menumbuhkembangkan pribadi yang arif, bijaksana, berkarakter, dan bernilai sesuai dengan norma sosial dimasyarakat karena sastra itu sendiri merupakan cerminan kehidupan yang sebagian besar menyajikan kenyataan sosial (Adhi Dwipayana \& Sidi Artajaya, 2018). Namun keniscayaan relevansi antara kehidupan sosial dengan amanah satua dewasa ini kian memudar. Teks satua yang sesungguhnya telah terinternalisasi dengan tata nilai kebajikan yang amat penting bagi pendidikan karakter anak mulai dilupakan. Bahkan dalam kenyataannya, dewasa ini tidak jarang tersiar pemberitaan tentang anak yang berprilaku tidak sesuai dengan norma-norma tersebut.

Di tengah merosotnya moralitas dan karakter anak-anak saat ini, maka penanaman ajaran moral melalui nilai-nilai dalam satua sangatlah penting untuk dilakukan. Upaya penggalian, sosialisasi, serta internalisasi tata nilai tersebut di kalangan anak-anak tentu harus diawali dengan pemahaman masyarakat tentang amanat melalui analisis nilai satua itu sendiri.

Salah satu satua yang dapat dijadikan sebagai pedoman dalam kehidupan manusia adalah satua Men Tiwas Teken Men Sugih. Melalui sifat-sifat yang ditunjukkan oleh tokoh Men Tiwas, tulisan ini menjadi penting untuk mengungkap pesan moral mengenai tingkah laku yang patut ditiru dan senantiasa ditanamkan pada anak.

\section{METODE}

Metode yang digunakan dalam penulisan ini yakni metode deskriptif kualitatif. Metode sebagai suatu kegiatan ilmiah yang terencana, terstruktur, dan sistematis serta memiliki tujuan tertentu baik praktis maupun teoritis (Raco, 2010). Melihat dari data primer yang digunakan yakni berupa kata-kata atau teks, maka metode deskriptif kualitatif dirasa tepat untuk mendukung penyelesaian tulisan ini. Data yang berupa kata atau teks tersebut kemudian dianalisis dan diinterpretasikan sehingga diperoleh hasil yang terurai kembali dalam bentuk deskripsi kata/teks. Seperti makna dari satua Men Tiwas Teken Men Sugih, khususnya mengenai tingkah laku atau sifat yang patut dijadikan pedoman dalam menjalani kehidupan sehari-hari berdasarkan penokohan tokoh Men Tiwas, akan dapat dipaparkan dengan rinci dalam hasil yang bukan berupa angka statistik, melainkan dalam bentuk kata-kata.

\section{HASIL DAN PEMBAHASAN}

Sebagai salah satu bagian dari sastra, pemaknaan satua Men Tiwas Teken Men Sugih dapat dilakukan dengan pendekatan semiotik. Semiotik merupakan ilmu yang mempelajari tentang tanda-tanda. Tanda itu sendiri sebagai sesuatu yang atas dasar konvensi sosial yang terbangun sebelumnya dianggap mewakili sesuatu yang lain.Tanda dimaknai sebagi sesuatu hal yang merujuk pada hal lainnya (Wibowo, 2013).

Charles Sander Peirce adalah salah satu tokoh penting dalam Semiotika. Teori Peirce sering disebut sebagai grand theory dalam semiotika karena gagasannya bersifat menyeluruh berupa deskripsi struktural dari semua penandaan. Lebih lanjut mengenai pendapat Peirce membagi tanda menjadi 3 (tiga) jenis. Jenis-jenis tanda yang utama ialah ikon, indeks, dan simbol (Pradopo, 2010). Maka berdasarkan teori semiotik Peirce, berikut akan diuraikan nilai-nilai yang tersirat dibalik penokohan Men Tiwas.

\section{Suka Menolong}

Jenis tanda pertama dari tokoh Men Tiwas adalah ikon penolong. Ikon adalah salah satu jenis tanda yang diungkap Peirce. Ikon sebagai tanda yang menunjukkan adanya hubungan yang bersifat alami antara penanda dan petandanya (Pradopo, 2010). Hubungan tersebut semacam hubungan persamaan. Tanda ini bisa dikatakan mengandung kemiripan rupa. Sehingga tanda tersebut mudah dikenali oleh pemakainya. Proses pemahaman terhadap tanda jenis ikon 
dapat dilakukan hanya dengan melihat tanda itu sendiri. Seperti yang terdapat pada kutipan satua berikut :

"Yadin ia tiwas buka keto nanging solahne melah, demen ia matetulung, jemet maturan, lan setata mabikas sane beneh."

Terjemahan :

Walaupun dia miskin tetapi sifatnya baik, suka menolong, rajin sembahyang, dan selalu bertingkah laku yang baik dan benar.

Saat mengawali cerita, disebutkan dengan jelas bahwa Men Tiwas adalah sosok perempuan yang suka menolong. Maka ada hubungan yang terbangun secara alami dari penuturan cerita dengan tanda yang dimaksud.

Sifat suka menolong Men Tiwas juga ditunjukkan dari kutipan selanjutnya yakni,

"Buin manine Men Sugih nundenin Men Tiwas ngopin nebukang padi lan nyanjiang upah baas duang crongcong. Men Tiwas nyak nebukang padine Men Sugih. Nganti tengai mare ia suud."

Terjemahan :

Keesokan harinya, Men Sugih menyuruh Men Tiwas membantu menumbuk padi dan dijanjikan akan diberi upah berupa beras. Men Tiwas kemudian bersedia menumbuk padi milik Men Sugih sampai siang hari.

Kutipan di atas merupakan kejadian kedua kalinya Men Sugih menyuruh Men Tiwas melakukan sesuatu. Berbeda dengan sebelumnya, penanda yang ditunjukkan oleh karakter Men Tiwas tidak dapat diungkapkan begitu saja, melainkan membutuhkan penafsiran yang lebih mendalam. Jenis tanda ini disebut indeks. Indeks merupakan tanda yang menunjukkan hubungan kausal atau sebab-akibat antara penanda dan petandanya (Pradopo, 2010). Keterkaitan ini merujuk pada sesuatu yang fenomenal atau eksistensial. Tanda dan penanda dalam indeks juga memiliki sifat kongkret dan aktual. Cara menemukan petanda dalam indeks adalah dengan perkiraan terhadap penanda yang ada.
Meskipun sebelumnya Men Tiwas telah dikelabui oleh Men Sugih, dan untuk kedua kalinya dijanjikan upah yang tidak seberapa, namun Men Tiwas tetap bersedia membantu Men Sugih menumbuk padi sampai selesai. Hal ini merujuk pada perkiraan bahwa Men Tiwas melakukan hal itu karena sifat dasar Men Tiwas yang suka menolong orang lain.

\section{Gigih, Pantang Menyerah, dan Giat Bekerja}

Sifat Men Tiwas lainnya adalah gigih, pantang menyerah, dan giat bekerja. Dalam kondisi yang serba kekurangan, Men Tiwas selalu bersedia mengerjakan syarat yang diberikan oleh Men Sugih. Hal ini ia lakukan semata-mata dengan tujuan agar dapat memenuhi kebutuhannya sehari-hari. Ini menunjukkan adanya keterikatan hubungan sebab akibat. Tanda bahwa Men Tiwas memiliki sifat gigih, pantang menyerah, dan giat bekerja diperoleh dari penafsiran kutipan berikut :

"Nah lakar kebaang nyai api, kewala opin malu ngaliin kutu di sirah wakene. Aliin nganti kedas sirah wakene nyanan baanga ja upah baas acrongcong" keto pesautne Men Sugih. Nyak lantas Men Tiwas ngaliin kutune Men Sugih nganti tengai mare suud. Men Tiwas lantas baanga upah baas acrongcong teked jumahne baase ento jakana."

Terjemahan :

Kata Men Sugih, "Ya, aku akan memberikanmu api, tapi kau harus membantu mencari kutu di rambutku terlebih dahulu. Cari sampai bersih, nanti akan kuberikan kau beras sebagai upahnya." Men Tiwas kemudian mencari kutu di kepala Men Sugih sampai siang hari. Lalu Men Tiwas diberikan upah berupa beras dan langsung dimasak ketika ia sampai di rumah.

Dengan pemerolehan tanda melalui proses penafsiran, maka tanda ini tergolong indeks. Sifat giat bekerja Men Tiwas juga dapat dilihat dari pekerjaannya mencari kayu 
bakar dan sayur pakis di hutan yang ia lakukan tanpa mengeluh sedikitpun, seperti yang diperkirakan melalui kutipan berikut :

"Sedek dina anu Men Tiwas kemu ka alase ngalih saang teken paku."

Terjemahan :

Suatu hari, Men Tiwas ke hutan mencari kayu bakar dan daun pakis.

\section{Bersyukur dan Tidak Lupa Diri}

Pada hakikatnya analisis semiotik memang digunakan untuk mengungkap sesuatu dibalik sesuatu. Menguraikan halhal yang masih perlu dipertanyakan lebih dalam setelah membaca teks atau mendengarkan wacana tertentu. Dalam kajian tentang semiotika teks mengungkapkan bahwa semiotika merupakan teori yang menjabarkan tentang hubungan tanda dengan penandanya di dalam sebuah sistem dengan aturan dan kesepakatan tertentu, serta mempelajari peran dari tanda itu sendiri dalam kehidupan sosial masyarakat (Piliang, 2004).

Mempertanyakan lebih dalam, mengungkap sesuatu dibalik sesuatu tentu patut dilakukan ketika sesuatu itu dirasa aneh, seperti kutipan berikut :

"Eh Men Tiwas, yen nyai nyak nyeluk jit nirane, ditu ada pabaang nira tekening nyai!'. Men tiwas lantas nyak nyeluk jit kidange ento. Mara kedenga limane bek misi emas. Kendel pesan Men Tiwas maan mas bek pesan. Mara konanga Men Tiwas lakar ngaturang suksma teken Sang Kidang, lautan Sang Kidang suba ilang."

Terjemahan :

"Eh Men Tiwas, jika engkau mau memasukkan tangan ke dalam pantatku, akan ada hadiah untukmu!" Men Tiwas lalu bersedia memasukkan tangan ke pantat kijang itu. Setelah ditarik, tangan Men Tiwas berisi banyak emas. Baru saja Men Tiwas akan mengucapkan terima kasih pada Sang Kidang, namun Sang Kidang tiba-tiba menghilang.

Dengan menghadirkan sosok Sang Kidang (kijang) yang menyuruh Men Tiwas memasukkan tangan ke pantatnya, ke bagian tubuh yang merupakan tempat mengeluarkan kotoran, satua ini ingin mempertegas betapa pasrahnya sosok Men Tiwas dalam menjalani kehidupannya. Bahkan sesuatu yang rasanya enggan dilakukan oleh orang lain, dengan ikhlas dilakukan olehnya.

Kutipan di atas juga memunculkan penafsiran bahwa dengan kepasrahannya, Men Tiwas yang merupakan wanita miskin dan tidak pernah mempunyai harta benda, meskipun mendapatkan hadiah emas melimpah, ia tidak serta merta lupa diri. Ia masih ingat mengucapkan terima kasih pada Sang Kidang yang memberikannya emas. Meskipun niat baik Men Tiwas tersebut tidak sempat ia lakukan karena Sang Kidang tibatiba menghilang. Ini membuktikan bahwa Men Tiwas menjadi sosok yang selalu mensyukuri apapun yang diperolehnya.

\section{Religius}

Sesuai dengan pengertian jenis tanda pertama yaitu ikon, maka di awal cerita dengan gamblang telah disebutkan bahwa Men Tiwas adalah sosok perempuan yang rajin bersembahyang. Dengan segala keterbatasannya, ia tetap menjadi wanita yang tidak pernah melupakan Tuhan. Hal ini relevan dengan sifat selalu bersyukur yang dimiliki oleh Men Tiwas. Kutipan yang menunjukkan sifat religius Men Tiwas yakni

"Yadin ia tiwas buka keto nanging solahne melah, demen ia matetulung, jemet maturan, lan setata mabikas sane beneh."

Terjemahan :

Walaupun dia miskin tetapi sifatnya baik, suka menolong, rajin sembahyang, dan selalu bertingkah laku yang baik dan benar.

\section{Kasih Sayang}

Men Tiwas sebagai wanita yang gigih dan giat bekerja, ia juga memiliki kasih sayang pada keluarga. Yang dalam satua ini ditafsirkan melalui sikap menyayangi anaknya. Hal ini terlihat dari kutipan: 
"Ia teken pianakne mekejang nganggo bungah dugase mablanja ka peken." Terjemahan :

Ia dan anaknya menggunakan perhiasan saat berbelanja ke pasar.

Dengan memperkirakan kutipan di atas, tanda indeks ini menunjukkan bahwa sebagai ibu, ia tidak hanya memikirkan dirinya sendiri. Terbukti dengan ia juga memberikan dan memakaikan emas yang ia dapatkan pada anaknya. Ini menunjukkan bahwa Men Tiwas sangat menyayangi anaknya.

\section{Perempuan Jujur}

Makna kejujuran yang disiratkan melalui tokoh Men Tiwas dapat ditafsirkan dengan kejadian ketika Men Sugih menagih kembali beras yang sebelumnya telah Men Sugih berikan kepada Men Tiwas. Meskipun beras tersebut sudah terlanjur dimasak, namun Men Tiwas tetap menjawab dengan jujur, bukan menyembunyikan atau membohongi Men Sugih. Men Tiwas yang polos tidak berdaya melawan Men Sugih, dan membiarkan beras yang sudah dimasak itu diambil kembali oleh Men Sugih.

"Baase busan suba bakat jakan tiang mbok" Men Tiwas nyautin.

"Nah ento suba mai aba, kadong ja suba dadi nasi!" lantas Men Sugih nyemak baase ane lakar lebeng dadi nasi ento."

Terjemahan :

"Beras tadi sudah terlanjur saya masak kak," kata Men Tiwas. "Walaupun sudah menjadi nasi, kembalikan padaku".

Sifat jujur yang ditunjukkan oleh Men Tiwas berikutnya adalah ketika ia menggunakan perhiasan yang didapat dari emas pemberian Sang Kidang. Perhiasan yang dikenakan oleh Men Tiwas tersebut menarik perhatian Men Sugih. Men Tiwas dengan jujur menjelaskan pada Men Sugih bahwa ia mendapatkan emas tersebut dari Sang Kidang yang tidak sengaja ia temui di hutan saat mencari kayu bakar dan daun pakis. Hal ini lebih jelas dapat dilihat melalui kutipan:
"Men Tiwas, dija nyai maan emas kene ebekne?" "Kene mbok, ibi tiang ngalih saang teken paku. Saget teka kidang bisa ngomong nunden nyelek jitne. Nyak lantas tiang, mara kedeng adi bek limane misi emas" keto Men Tiwas nyatuaang undukne ibi.

Terjemahan :

"Men Tiwas, dimana kamu dapat emas yang begitu banyak?" "Begini kak, kemarin saya mencari kayu bakar dan daun pakis. Tiba-tiba datanglah seekor kijang yang bisa bicara dan menyuruh saya untuk memasukkan tangan ke pantatnya. Saya mau melakukannya, saat saya menarik tangan saya, tibatiba tangan saya dipenuhi emas." Demikian penjelasan dari Men Tiwas.

Selain itu terdapat pula jenis tanda ketiga yakni simbol yang merupakan tanda untuk menunjukkan bahwa tidak ada hubungan alamiah antara penanda dan petandanya. Hubungan ini bersifat konvensional dan arbitrer atau semaumaunya. Simbol muncul sesuai kesepakatan atau konvensi sejumlah orang atau masyarakat. simbol merupakan sesuatu yang bisa dianalogikan sebagai kata yang telah terkait dengan penafsiran pemakai, kaidah pemakaian sesuai dengan jenis wacana, dan kreasi pemberian makna sesuai dengan intensi pemakai (Setiawan \& Maria M, 2020). Tanda-tanda kebahasaan pada umumnya adalah simbol-simbol. Proses kerja dari simbol yakni dengan mempelajari kesepakatan-kesepakatan tersebut.

Penyebutan kata "Men" dalam tokoh Men Tiwas maupun Men Sugih merupakan simbol ibu atau perempuan yang telah memiliki anak yang merupakan tanda kebahasaan di daerah Bali. Dengan judul yang menukik pada sebuah tanda perempuan, satua ini jelas menempatkan sosok ibu pada posisi yang sangat sentral. Sebagai sosok terpenting dalam perkembangan kepribadian anak, karena ibu adalah dunia pertama seorang anak dari semenjak ia akan dilahirkan. Maka dari itu pemilihan penanda "Men" (ibu) dalam satua ini dapat pula ditafsirkan lebih dalam, bukan hanya sebatas 
perempuan yang melahirkan anak, melainkan menyiratkan sebuah dunia yang terdekat dan pertama dikenal anak, yaitu keluarga. Jadi dalam perkembangannya, tentu bukan hanya ibu yang melahirkan anak saja yang bertanggung jawab terhadap perkembangan kepribadian, melainkan semua pihak, baik ayah, keluarga dan lingkungan haruslah bisa menjalankan peran "ibu" yang seyogyanya memberikan contoh dan panutan bagi anakanak dengan sifat kejujuran sebagai pondasi utamanya.

\section{Rendah Hati}

Men Tiwas yang sekarang sudah menjadi kaya (sugih) tidak menunjukkan sikap arogan. Sejalan dengan makna kejujuran di atas menunjukkan Men Tiwas tidak ada niat sama sekali untuk menjadi kaya seorang diri. Ia tidak takut bila ada orang lain yang mungkin bisa menjadi kaya seperti dirinya. Sebagai jenis tanda kategori indeks, hal ini dapat ditafsirkan dengan Men Tiwas yang jujur menceritakan pada Men Sugih asal mula ia mendapatkan emas. Ini menunjukkan bahwa, meskipun sudah menjadi kaya dan orang yang berada, Men Tiwas tidak berubah menjadi sombong. Ia tetap rendah hati. Menceritakan dengan ikhlas dimana ia memperoleh emas tersebut pada Men Sugih, wanita yang selalu mengelabuinya.

\section{SIMPULAN}

Sifat-sifat Men Tiwas yang terurai dari pemaknaan satua Men Tiwas teken Men Sugih diantaranya : suka menolong, gigih, pantang menyerah, giat bekerja, senantiasa bersyukur, tidak lupa diri, religius, penuh kasih sayang, jujur, dan rendah hati. Semua sifat ini merupakan nilai kebajikan yang wajib ditanamkan pada diri setiap anak mulai dari "dunia" terdekatnya. Dengan menumbuhkembangkan sifat-sifat ini, maka mutu dari nilai kemanusiaan pada anak akan senantiasa meningkat. Ketika anak mampu menerapkan nilai-nilai kemanusiaan, maka anak akan tumbuh menjadi manusia yang memiliki kepribadian dan bekarakter.

\section{DAFTAR PUSTAKA}

Adhi Dwipayana, I. K., \& Sidi Artajaya, G. (2018). Hegemoni Ideologi Feodalistis dalam Karya Sastra Berlatar Sosiokultural Bali. Jurnal Kajian Bali (Journal of Bali Studies), $\quad$ 8(2), 85-105. https://doi.org/10.24843/jkb.2018.v0 8.i02.p06

Andayani, Ni Made Juli; Linggih, I Nyoman; Wiradnyana, I. M. (2017). Satua Cupak teken Grantang (Pamastika Psikologi Tokoh). Jurnal Penelitian Agama Hindu, 1(1), 1-4. https://doi.org/http://dx.doi.org/10.2 5078/jpah.v1i1.122

Indhra, Feerlie Moonthana; Karim, M. N. (2018). Sastra Lisan Krinok: Kajian Struktural dan Semiotik. Dikbastra Jurnal Pendidikan Bahasa Dan Sastra, 1(1), 65-78. https://onlinejournal.unja.ac.id/dikbastra/article/vi ew/5834

Laksmi, N. L. G. E. (2014). Tutur Ardhasmara Analisis Struktur dan Semiotika. Humanis Journal of Arts and Humanities, 7(1), 1-8.

Piliang, Y. A. (2004). Semiotika Teks :Sebuah Pendekatan Analisis Teks. MediaTor Jurnal Komunikasi, 5(2), 189-198. https://doi.org/10.29313/MEDIATO R.V5I2.1156.G715

Pora, S. (2014). Tinjauan Filosofis Kearifan Lokal Sastra Lisan Ternate. Jurnal UNIERA, 3(1), 112-121. https://journal.uniera.ac.id/pdf_repos itory/juniera69-3WWxODa921F00MRMA5jlFZkh.pdf

Pradopo, R. D. (2010). Beberapa Teori Sastra, Metode Kritik, dan Penerapannya. Pustaka Pelajar.

Raco, J. R. (2010). Metode Penelitian Kualitatif (Jenis, Karakter, dan Keunggulannya). PT. Grasindo.

Santosa, P. (2012). Kearifan Budaya dan Fungsi Kemasyarakatan dalam Sastra Lisan Kafoa. METASASTRA: Jurnal Penelitian Sastra, 5(1), 6782. 
https://doi.org/10.26610/metasastra. 2012.v5i1.67-82

Setiawan, A., \& Maria M, H. E. H. (2020). Analisis Nilai Pendidikan Moral Novel Rembulan Tenggelam di Wajahmu: Pendekatan Semiotik
Peirce. Jurnal Pembelajaran Bahasa Dan Sastra Indonesia , 1(1), 8-17. https://ojs.unm.ac.id/Indonesia/articl e/view/12390

Wibowo, I. S. W. (2013). Semiotika Komunikasi. Mitra Wacana Media. 